\title{
Seminal Vesicle-Rectal Fistula Secondary to Anastomotic Leakage After Low Anterior Resection for Rectal Cancer: A Case Report and Brief Literature Review
}

Masato Kitazawa, Manabu Hiraguri, Chika Maeda, Mizukami Yoshiki, Naoto Horigome, Gengo Kaneko

Department of Gastrointestinal Surgery of Iida Municipal Hospital, Masato Kitazawa, Iida, Japan

\begin{abstract}
We report a case of a patient with seminal vesicle-rectal fistula, an extremely rare complication of low anterior resection of the rectum. A 53-year-old man with rectal adenocarcinoma underwent low anterior resection in our hospital. The patient experienced diarrhea, pneumaturia, and low-grade fever on postoperative day 13. A computed tomography scan showed emphysema in the right seminal vesicle. We concluded that anastomotic leakage induced a seminal vesicle-rectal fistula. The patient underwent conservative therapy with total parenteral nutrition and oral intake of metronidazole. Diarrhea and pneumaturia rapidly improved after metronidazole administration and the patient was successfully cured without invasive therapy such as colostomy or surgical drainage. A seminal vesicle-rectal fistula is a rare complication of low anterior resection, and therapeutic strategies for this condition remain elusive. Our report provides valuable information on the successful conservative treatment of a secondary seminal vesicle-rectal fistula that developed after low anterior resection of the rectum in a patient.
\end{abstract}

Key words: Seminal vesicle-rectal fistula - low anterior resection - rectal cancer

Ceminal vesicle-rectal fistula is a rarely encoun$\checkmark$ tered complication in patients. The reported causes of this condition are Crohn's disease, ${ }^{1,2}$ diverticulitis, ${ }^{3-6}$ operative complications of the prostate, ${ }^{7,8}$ direct invasion of rectal cancer, ${ }^{9}$ congenital anomalies, $^{10}$ iatrogenic perforation by transrectal

Corresponding author: Masato Kitazawa, Department of Gastrointestinal Surgery, Iida Municipal Hospital, 438 Yahata-machi, Iida City, Nagano \#395-0814, Japan.

Tel.: +81-265-21-1255, Fax: +81-265-21-1266; E-mail: kitazawa0118@gmail.com 

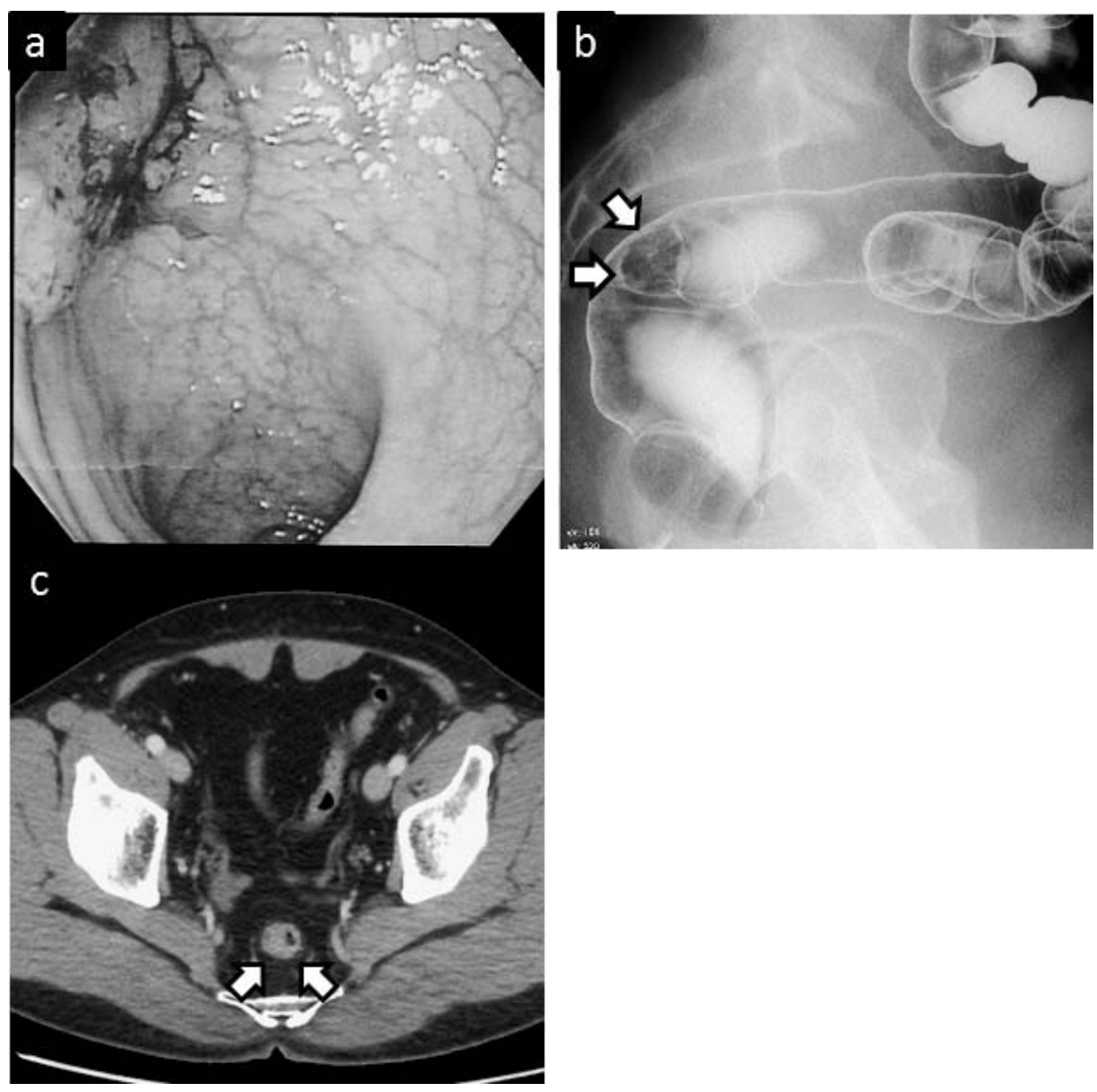

Fig. 1 Preoperative imaging findings. (a) Colonoscopy shows a tumor lesion in the rectum. (b) Barium enema shows an elevated lesion [arrows in (b)] in the rectum above the peritoneal reflex. (c) CT scan revealed wall thickness [arrows in [(c)] of rectum.

aspiration or seminal vesicle abcess, ${ }^{11}$ secondary vesiculitis, $^{12}$ and anastomotic leakage after low anterior resection (LAR) of the rectum. ${ }^{2,13-18} \mathrm{We}$ could find only 9 reported cases of seminal vesiclerectal fistula after LAR in the PubMed database.

Here, we present a case of a seminal vesicle-rectal fistula that developed after LAR in a patient and review the clinical manifestation, radiographic findings, and treatment procedure for this condition.

\section{Case Report}

A 53-year-old man was admitted to our hospital for an operation for rectal cancer. The patient had no history of health disorders. He had occasional melena and was diagnosed with adenocarcinoma in the rectum above the peritoneal reflection (Ra) on colonoscopy (Fig. 1a) and barium enema examinations (Fig. 1b). Additionally, computed tomography (CT) indicated that the preoperative diagnosis was adenocarcinoma located in the $\mathrm{Ra}$, invading the muscularis propria without lymph node involvement and distant metastases (Fig. 1c). The patient underwent LAR of the rectum with D3 lymph node dissection, which was performed in the manner usually employed in Japan. A double-stapling technique using a $28-\mathrm{mm}$ circular stapler was employed. The tissue rings were completely intact, and the anastomosis was noted to be airtight at the time of the operation. We placed a drainage tube near the anastomotic site. The postoperative pathologic diagnosis was a well-differentiated adenocarcinoma invading the muscularis propria without lymph node involvement and liver metastasis (T2, N0, M0, Stage I).

The patient's condition was stable in the immediate postoperative period; however, on postoperative day (POD) 4, his body temperature rose to $38.3^{\circ} \mathrm{C}$ without symptoms such as abdominal pain and purulent drainage. Although we could not 

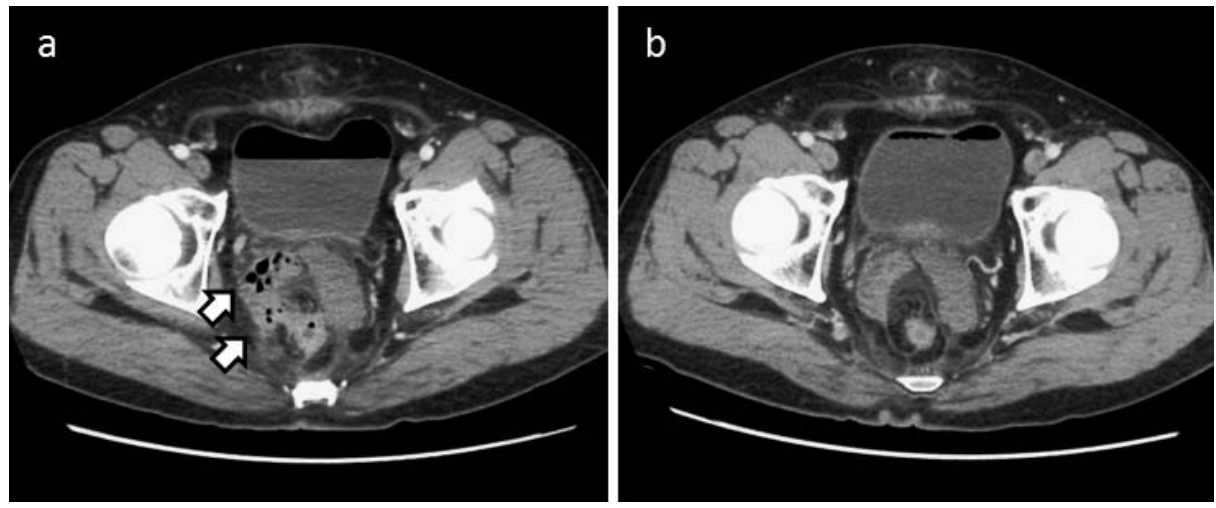

Fig. 2 Postoperative Computed Tomography. (a) On POD 16, CT scan shows emphysematous findings in the right seminal vesicle [large arrows in (a)] and the abnormal air in the bladder [small arrows in (a)]. (b) On POD26, CT scan shows no emphysematous findings in the right seminal vesicle, but small amount air in the bladder.

detect any infectious causes, the antibiotic was changed from flomoxef to meropenem on suspicion of surgical-site infection. The patient's fever reduced rapidly and was then allowed oral intake on POD 6, and the drainage tube was removed on POD 9. The patient was expected to be discharged, but he had diarrhea from POD 10 and had a high fever on POD 12. He was suspected to have cholecystitis or cholangitis because of mild epigastralgia, elevated levels of transaminase and biliary tract enzymes on biochemical blood tests, and debris in the swollen gallbladder on ultrasonographic examination. Further, he was treated with cefoperazone-sulbactam under fasting conditions. Diarrhea and fever initially improved but relapsed despite continuing the antibiotic treatment. Moreover, the patient developed pneumaturia on POD 16. CT scan showed emphysematous findings in the right seminal vesicle (Fig. 2a). At that time, the patient tested positive for fecal Clostridium difficile toxin. Therefore, he was diagnosed with antibiotic-associated colitis. We considered that an anastomotic leakage induced a seminal vesicle-rectal fistula with antibiotic-associated colitis. The patient had no severe symptoms and underwent conservative therapy with total parenteral nutrition and metronidazole intake. Diarrhea, pneumaturia, and fever rapidly improved with metronidazole therapy. After 10 days of metronidazole therapy, the emphysematous finding in the right seminal vesicle disappeared completely on a CT scan (Fig. 2b). Moreover, rectoscopy revealed a possible site of anastomotic leakage (Fig. 3a), and we confirmed that the fistula was already closed by Gastrografin contrast study (Fig. $3 b)$. Therefore, the patient was allowed to start oral intake. Since then, he had no pneumaturia but had a cloudy urine and occasional low-grade fever. He was therefore treated with minomycin targeting the enterococcal infection in the bladder and was cured
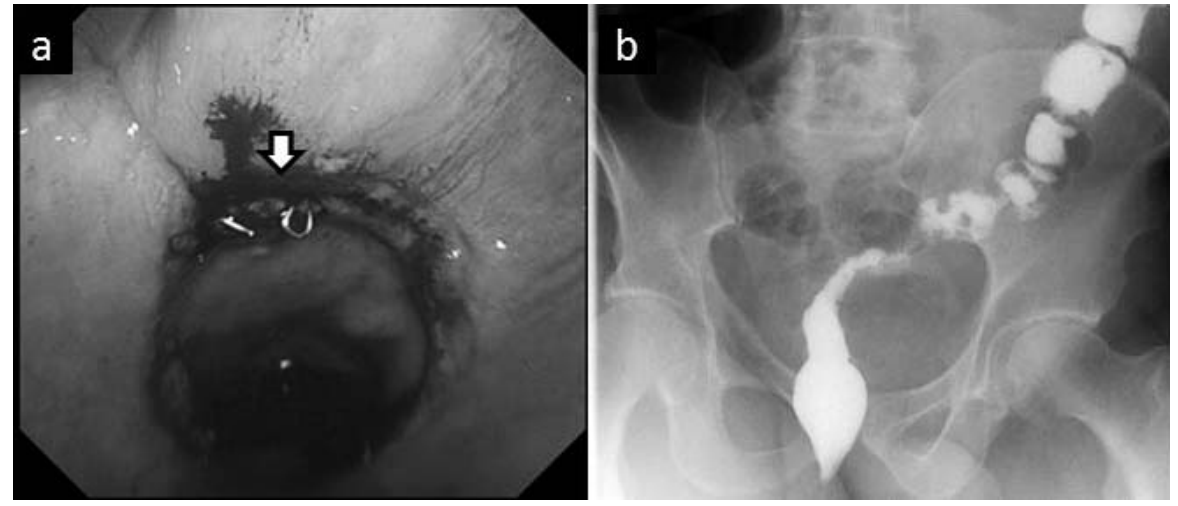

Fig. 3 Imaging findings on POD27. (a) Rectoscopy shows a possible site [arrow in (a)] of anastomotic leakage. (b) Gastrografin contrast study shows no fistula between the anastomotic site and seminal vesicle. 
Table 1 Reported cases of the seminal vesicle-rectal fistula after low anterior resection of the colon

\begin{tabular}{|c|c|c|c|c|c|c|c|}
\hline Author & Year & Age & Symptom & Onset & Diagnostic modality & Treatment & Prognosis \\
\hline Goldman HS $^{13}$ & 1989 & 76 & $\begin{array}{l}\text { Pneumaturia, } \\
\text { testicular pain }\end{array}$ & 1 month & $\begin{array}{l}\text { Water-soluble contrast } \\
\text { enema }\end{array}$ & Cutaneous vasostomy & Remission \\
\hline Thomas $\mathrm{A}^{14}$ & 1994 & 32 & $\begin{array}{l}\text { Urethral discharge } \\
\text { dysuria, fever }\end{array}$ & 1 month & Not recorded & Surgical drainage & $\begin{array}{l}\text { Remission } \\
\text { (dying of cancer) }\end{array}$ \\
\hline Carlin $\mathrm{J}^{2}$ & 1999 & 64 & Not recorded & 2 months & CT & Surgical drainage & Remission \\
\hline Placer $C^{15}$ & 2007 & 60 & $\begin{array}{l}\text { Pneumaturia, } \\
\text { fecaluria }\end{array}$ & $\begin{array}{l}9 \text { weeks } \\
\text { (10 days) }\end{array}$ & $\mathrm{CT}$ & Conservative therapy & Remission \\
\hline Kawasaki $\mathrm{S}^{16}$ & 2008 & 52 & Pneumaturia & 2 weeks & $\begin{array}{r}\mathrm{CT} \text {, water-soluble } \\
\text { contrast enema }\end{array}$ & Colostomy & Remission \\
\hline Sykora $\mathrm{R}^{17}$ & 2012 & 66 & $\begin{array}{l}\text { Pneumaturia, fever, } \\
\text { scrotal swelling }\end{array}$ & 11 days & $\begin{array}{r}\mathrm{CT} \text {, water-soluble } \\
\text { contrast enema }\end{array}$ & Colostomy & Remission \\
\hline Nakajima $\mathrm{K}^{18}$ & 2013 & 73 & $\begin{array}{l}\text { Pneumaturia, } \\
\text { testicular pain, } \\
\text { fever }\end{array}$ & 1 month & $\mathrm{CT}$, vesiculography & Conservative therapy & Remission \\
\hline Nakajima $\mathrm{K}^{18}$ & 2013 & 76 & $\begin{array}{l}\text { Pneumaturia, } \\
\text { testicular pain, } \\
\text { scrotal swelling }\end{array}$ & 2 weeks & $\mathrm{CT}$, contrast enema & Colostomy & Remission \\
\hline Nakajima $K^{18}$ & 2013 & 49 & $\begin{array}{l}\text { Fecaluria, fever, } \\
\text { scrotal swelling }\end{array}$ & 1 week & $\mathrm{CT}$ and vasogram & Muscular flap & Remission \\
\hline Our Case & 2013 & 53 & Pneumaturia, fever & 13 days & $\mathrm{CT}$ & Conservative therapy & Remission \\
\hline
\end{tabular}

within several days. Finally, he was discharged on POD 41.

\section{Discussion}

The anastomotic site in LAR is located close to the seminal vesicles in male patients and close to the vagina in female patients. Rectal-vaginal fistula is a well-known complication of LAR, whereas seminal vesicle-rectal fistula is a rarely encountered complication. We could find only 9 reported cases of this condition in the PubMed database (Table 1). This complication is characterized by a late onset, as compared with usual anastomotic leakage after LAR. In the reported cases, the earliest onset was at 1 week after surgery and the latest onset was at 9 weeks. Placer ${ }^{15}$ reported an atypical case with the latest onset. The patient underwent LAR with cover ileostomy and stoma closure 9 weeks later. On POD 10 of stoma closure the patient developed seminal vesicle-rectal fistula with pneumaturia and fecaluria. Pneumaturia was a characteristic symptom of the seminal vesicle-rectal fistula in 6 of the 8 described reports, and CT and contrast enema examinations were the most useful diagnostic modalities. The key diagnostic findings were emphysematous seminal vesicles on $\mathrm{CT}$ and a fistula from the rectum to the seminal vesicles on contrast enema examinations.

Seven patients were treated with surgical procedures, whereas the other 2 patients were success- fully treated with conservative therapy. In the present case, the patient's general condition was good, and his CT scan showed localized emphysema without peripheral abscess formation and inflammatory findings. Consequently, the patient chose to undergo conservative therapy, and he was successfully cured.

In many reports, a pelvic abscess rupture was considered as the cause of the seminal vesicle-rectal fistula. If this is true, then we can easily understand the reason underlying the late onset of this complication and the intractable nature of this fistula, similar to that of a perianal abscess or anal fistula. However, in the present case, the CT scan did not show the presence of an abscess or remains of an abscess in the pelvic cavity. We hypothesized the pathogenic process of this condition as follows: Antibiotic-related colitis caused inflammation of the anastomotic site. The weak, inflamed anastomotic site was perforated by frequent bowel movements, leading to the formation of the seminal vesicle-rectal fistula. The patient recovered after metronidazole treatment without using common antibiotics, and we believe that the antibiotic-associated colitis induced this complication.

This complication mostly induces localized inflammation and rarely induces panperitonitis or severe systemic inflammation. Therefore, patients with this complication have enough time to choose between surgical and conservative therapies. Our report provides valuable information regarding the 
use of conservative therapy for the successful treatment of this complication in a patient.

\section{References}

1. Hamidina A. Recto-ejaculatory duct fistula: an unusual complication of Crohn's disease. J Urol 1984;131(1):123-124

2. Carlin J, Nicholson DA, Scott NA. Two cases of seminal vesicle fistula. Clin Radiol 1999;54(5):309-311

3. Godec CJ, Rice D, Younger S. Recurrent chronic epididymitis as an initial symptom of colovesical fistula. N Y State J Med 1985;85(5):222-224

4. O'Brien WM, Lynch JH. Epididymitis-an unusual presentation of colovesical fistula secondary to diverticulitis. Report of a case. Dis Colon Rectum 1988;31(7): 570-572

5. Coulier B, Ramboux A, Maldague P. Emphysematous epididymitis as presentation of unusual seminal vesicle fistula secondary to sigmoid diverticulitis: case report. Abdom Imaging 2005;30(1):113-116

6. LaSpina M, Facklis K, Posalski I, Fleshner P. Coloseminal vesicle fistula: report of a case and review of the literature. Dis Colon Rectum 2006;49(11):1791-1793

7. Calder JF. Seminal vesicle fistula. Clin Radiol 2000;55(4):328

8. Celebrezze JP Jr, Medich DS. Rectal ulceration as a result of prostatic branchytherapy: a new clinical problem: report of three cases. Dis Colon Rectum 2003;46(9):1277-1279

9. Roupret M, Varkarakis J, Valverde A, Sebe P. Recto-seminal fistula and cancer of the rectum. Prog Urol 2004;14(6):12191220

10. Daradka I, Hazza I. Ectopia vasa deferentia inguinal hernia, vesicourteric reflex, imperforate anus, and recto-vesical fistula: a case report. Saudi J Kidney Dis Transpl 2006;17(4): 572-575

11. Hammad FT. Seminal vesicle cyst forming an abscess and fistula with the rectum review of perianal drainage and treatment. Scand J Urol Nephrol 2006;40(5):426-428
12. Izumi K, Takase $\mathrm{Y}$, Kobayashi T, Tokunaga S, Namiki M. Seminal vesicle-rectal fistula with preceding right acute epididymitis. Urol Int 2007;78(4):367-369

13. Goldman HS, Sapkin SL, Foote RF, Taylor JB. Seminal vesiclerectal fistula. Report of a case. Dis Colon Rectum 1989;32(1):6769

14. Kollmorgen TA, Kollmorgen CF, Lieber MM, Wolff BG. Seminal vesicle fistula following abdominoperineal resection for recurrent adenocarcinoma of the rectum. Report of a case. Dis Colon Rectum 1994;37(12):1325-1327

15. Placer C, Elosegui JL, Andres Mujika J, Enriquez-Navascues JM. Symptomatic coloseminal vesicle fistula after radiochemotherapy and surgery for rectal cancer. Cir Esp 2007; 81(2): 110

16. Kawasaki S, Saito S, Hazama H, Tomioka H, Akamoto S, Okumoto T. Seminal vesicle-rectal fistula secondary to anastomotic leakage after leakage after low anterior resection for rectal cancer: report of a case. Jpn J Gastroenterol Surg 2008; 41(10):1854-1859

17. Sykora R, Krhut J, Jonszta T, Nemec D, Havranek O, Martinek L. Fistula between anterior rectum wall and seminal vesicles as a rare complication of low-anterior resection of the rectum. Wideochir Inne Tech Malo Inwazyjne 2012;7(1):63-66

18. Nakajima K, Sugito M, Nishizawa $Y$, Ito M, Nishizawa $Y$, Suzuki T. Rectoseminal vesicle fistula as a rare complication after low anterior resection: a report of three cases. Surg Today 2013;43(5):574-579

(C) 2014 Kitazawa et al.; licensee The International College of Surgeons. This is an Open Access article distributed under the terms of the Creative Commons Attribution Non-commercial License which permits use, distribution, and reproduction in any medium, provided the original work is properly cited, the use is non-commercial and is otherwise in compliance with the license. See: http://creativecommons.org/licenses/by-nc/3.0 